\title{
The influence of deficient retro-aortic rim on technical success and early adverse events following device closure of secundum atrial septal defects: an analysis of the IMPACT Registry ${ }^{\circledR}$ :
}

\section{Deficient retro-aortic rim and device closure of atrial septal defect}

\author{
Michael L O’Byrne, MD MSCE ${ }^{1}$, Matthew J Gillespie, MD², Kevin F Kennedy, MS ${ }^{4}$, Yoav \\ Dori, MD PhD², Jonathan J Rome, MD², and Andrew C Glatz, MD MSCE ${ }^{2,3}$ \\ ${ }^{1}$ Division of Cardiology, Children's National Medical Center and Department of Pediatrics George \\ Washington University School of Medicine and Health Sciences \\ 2Division of Cardiology, The Children's Hospital of Philadelphia and Department of Pediatrics \\ Perelman School of Medicine at The University of Pennsylvania \\ ${ }^{3}$ Center for Clinical Epidemiology and Biostatistics, Perelman School of Medicine at The \\ University of Pennsylvania \\ ${ }^{3}$ Mid America Heart Institute St. Luke's Health System
}

\begin{abstract}
Background-Concern regarding aortic erosion has focused attention on the retro-aortic rim in patients undergoing device closure of atrial septal defects (ASD), but its effect on early outcomes is not well studied.

Methods-A multi-center retrospective cohort study of patients undergoing device occlusion of ASD between 1/2011-10/2014 was performed, using data from the IMproving Pediatric and Adult Congenital Treatment Registry. Subjects were divided between those with retro-aortic rim $<5$ and $\geq 5 \mathrm{~mm}$. Primary outcomes were technical failure and major early adverse events. Case times were measured as surrogates of technical complexity. The effect of deficient retro-aortic rim on primary outcomes was assessed using hierarchical logistic regression, adjusting for other suspected covariates and assessing whether they represent independent risk factors
\end{abstract}

Results-1,564 subjects (from 77 centers) were included, with deficient retro-aortic rim present in $40 \%$. Technical failure occurred in 91 subjects (5.8\%) and a major early adverse event in 64 subjects (4.1\%). Adjusting for known covariates, the presence of a deficient retro-aortic rim was not significantly associated with technical failure (OR: $1.3,95 \%$ CI: $0.9-2.1)$ or major early adverse event (OR: $0.7,95 \%$ CI: $0.4-1.2)$. Total case $(p=0.01)$ and fluoroscopy time $(\mathrm{p}=0.02)$ were greater in subjects with deficient rim, but sheath time was not significantly different ( $p=0.07$ ). Additional covariates independently associated with these outcomes were identified.

Corresponding Author: Michael L O’Byrne, mlobyrne@ childrensnational.org, Division of Cardiology, Children's National Medical Center, Phone: (202) 476-2020, Fax: (202) 476-5700.

Disclosures: The other authors have nothing to disclose. 
Conclusion-Deficient retro-aortic rim was highly prevalent but not associated with increased risk of technical failure or early adverse events. Studies with longer follow-up are necessary to assess other outcomes, including device erosion.

\section{Keywords}

pediatric cardiology; outcomes research; heart catheterization

\section{Introduction}

Since catheter-based closure of atrial septal defects (ASD) was first reported by King and Mills in $1976^{1}$, device occlusion of ASD has been widely adopted. Device occlusion of ASD with the Amplatzer septal occluder (ASO, St. Jude Medical, St. Paul, MN, USA) has demonstrated excellent rates of technical success ${ }^{2-5}$, and favorable risk of adverse events compared to operative closure ${ }^{6-8}$. More recently, the Helex septal occluder (HSO, W.L. Gore and Associates, Newark, DE, USA) has shown similarly excellent outcomes ${ }^{9-12}$. Device erosion, a potentially catastrophic complication of the procedure, has received special attention. Deficient retro-aortic rim has been implicated as a potential risk factor for erosion $^{13}$, raising the question whether it contributes to risk of other adverse events.

The prevalence of deficient retro-aortic rim has been reported as $24 \%$ in adults ${ }^{14}$ and 59 $60 \%$ in children ${ }^{12,15,16}$. In a single-center case series, retro-aortic rim was not associated with increased risk of technical failure or major early adverse events ${ }^{15}$. However, the study was limited by the sample size and the limited variability in practice of a single center. We sought to address these limitations with a retrospective cohort study using data from the IMproving Pediatric and Adult Congenital Treatment (IMPACT ${ }^{\circledR}$ ) registry. IMPACT ${ }^{\circledR}$ is the largest clinical registry collecting information on pediatric and adult patients undergoing diagnostic and interventional cardiac catheterization procedures ${ }^{17-19}$. We performed a retrospective multicenter cohort study to determine if deficient retro-aortic rim was a risk factor for technical failure or major early adverse events. As an exploratory analysis we also sought to take advantage of this large cohort to identify other risk factors for technical failure and early major adverse events.

\section{Methods}

\section{Data source}

IMPACT $^{\circledR}$ is a clinical registry funded by the American College of Cardiology and managed by the National Cardiovascular Data Registry with data from 77 pediatric and general hospitals performing cardiac catheterizations in children and adults with congenital heart disease at the time of this analysis. Participating centers collect information on all patients undergoing cardiac catheterization, including patient demographics, medical/surgical history, procedural information and adverse events through hospital discharge. Data are recorded using standardized data elements and definitions. The database is subject to rigorous quality assurance standards ${ }^{20}$. Auditing procedures are still being developed ${ }^{18}$. The current study used data from IMPACT v1.0.1. The institutional review board of The Children's Hospital of Philadelphia reviewed the proposed project and determined that it did 
not represent human subjects research in accordance with the Common Rule (45 CFR 46.102(f)).

\section{Study population and study procedures}

The study population was identified by direct query of IMPACT ${ }^{\circledR}$ by analysts at Mid America Heart Institute. It included subjects of all ages who had an ASD closure procedure recorded in IMPACT ${ }^{\circledR}$. Exclusion criteria were multi-fenestrated ASD, additional interventions, and prior cardiac operation, restricting the sample to a homogenous population. Subjects with missing aortic rim data were also excluded from the primary analysis, because the rim measurement was our primary exposure. Several additional analyses were performed to determine whether excluding subjects with missing rim data introduced bias. These analyses are described in the section on statistical analysis.

Data collected included demographics, medical history, details of the ASD anatomy (static defect and septal lengths), hemodynamic data collected (ratio of pulmonary:systemic cardiac index), and details of the procedure (balloon-sizing, anesthesia at start of the case, device used, and presence of a trainee). The primary exposure was defined as deficient retro-aortic rim (aortic rim size $<5 \mathrm{~mm}$ ) and non-deficient retro-aortic rim ( $\geq 5 \mathrm{~mm}$ ), as used previously $13,15,16,21$. A primary exposure was chosen before analysis to insure that the distribution of other covariates was uniform between exposed and unexposed groups. Two primary outcomes were identified prior to analysis: technical failure (device malposition requiring re-intervention, embolization requiring re-intervention, residual shunt $23 \mathrm{~mm}$, or a device which was deployed, released, and recaptured) and the presence of any early major adverse event (death, cardiac arrest, new arrhythmia, new heart valve regurgitation, tamponade, air embolus, initiation of dialysis, embolic stroke, new extracorporeal membrane oxygenation, new ventricular assist device, unplanned cardiac, vascular, or other surgery, vascular complication requiring treatment, repeat catheterization (all prior to discharge)). For total counts, cases in which multiple technical failures or adverse events were only counted once. Within the primary outcomes, the individual events are also described for completeness' sake. Secondary outcomes were case times (fluoroscopy, sheath, and total case time), which were hypothesized to be surrogates for technical complexity.

\section{Statistical analysis}

Standard descriptive statistics were calculated. Continuous variables were expressed as mean \pm standard deviation or median (range and interquartile range (IQR)). Categorical variables were described as proportions and counts.

For primary and secondary outcomes, hierarchical multivariable models were used to adjust for confounders and clustering by institution. Risk factors for adverse outcome were included in the model without selection criteria based on published series ${ }^{12,14,15,22}$ and clinical suspicion. In addition to deficient retro-aortic rim, factors included were subject age, device used, sex, height, trainee present, static ASD diameter, and balloon-sizing technique used. No additional forward or backward selection was used to refine the model. This allowed us to stringently assess the influence of our primary exposure, and in an exploratory fashion to assess other potentially important risk factors. Logistic regression was used to 
analyze the primary outcomes, while linear regression was used for case times. Post-hoc secondary analyses were performed to investigate if 1 ) interaction between defect size and deficient retro-aortic rim or 2) inclusion of ratio of static defect size to septal length improved model fit.

An exploratory analysis was performed to determine if the threshold of $5 \mathrm{~mm}$ for deficient retro-aortic rim was the most informative. Restricted cubic splines were plotted using methods previously described ${ }^{23}$, estimating odds ratios across the range of retro-aortic rim dimensions to determine if there were other inflection points.

Because of concern raised after the initial analysis about the contribution of device choice on adverse outcomes, two additional analyses were performed: 1) comparing the observed risks of both primary outcomes by device used; and 2) assessing whether technical failure was treated in the initial catheterization, a second catheterization, or in a cardiac operation. Event rates were compared using Chi-square test or Fisher's Exact test as indicated.

Missing data were addressed in several ways. As described above, a significant portion of subjects in the initial query had missing rim measurements. To assess for bias introduced by this choice, baseline characteristics of subjects with missing rim measurements were compared to the study population (Supplemental Table 1), and sensitivity analyses including this group (with retro-aortic rim measurement coded as missing) (Supplemental Tables 2 and 3 ). For one covariate of clinical interest (balloon-sizing technique), there was a small proportion (1-2\%) in whom the data were missing, so a categorical variable for "missing" was added to allow for inclusion of the subjects ${ }^{24,25}$. For other variables, case elimination was utilized. A threshold for statistical significance was set at $p<0.05$. All data analysis was performed using SAS 9.4 (Cary, NC, USA)

\section{Results}

\section{Study population}

On initial query, 3,557 ASD closure procedures were performed during the study period. Of these 786 were excluded (156 for multiple ASD, 389 for multi-fenestrated ASD, 100 for additional procedures, and 141 for prior cardiac operations). Of the remaining 2,771 procedures, $43 \%(n=1,207)$ were missing retro-aortic rim measurements, resulting in an analytic cohort of 1,564 procedures from 74 centers (Figure 1). The population with missing rim data was significantly older $(p<0.001)$, had a higher proportion of adult patients $(p<0.001)$, had smaller static ASD diameter $(p=0.02)$, and a higher portion of subjects undergoing ASD closure for stroke prevention and treatment of migraine $(p<0.001)$ (Supplementary Table 1).

The cohort was 36\% ( $\mathrm{n}=564)$ male and $76 \%(\mathrm{n}=1184)$ white. The prevalence of deficient retro-aortic rim was $40 \%(\mathrm{n}=653) .43 \%$ of subjects underwent balloon sizing of the atrial septal defect. ASO devices were used in $70 \%$ of cases $(n=1098)$, HSO device in $21 \%$ $(\mathrm{n}=333)$, and Gore septal occluder or Cardioform device (GSO) in 5\% ( $\mathrm{n}=81)$. 
Differences in demographic, anatomic, and procedural characteristics between subjects with deficient and sufficient retro-aortic rims are summarized in Table 1 . The population with deficient retro-aortic rim was younger (median age: 5 years IQR: 4-11 vs. 7 years IQR: 4$15, p<0.001)$, had a higher proportion of subjects who were black $(p=0.02)$, had shorter total septal length $(p<0.001)$, and larger balloon-sized defects in the subset who underwent balloon sizing using stretch technique ( $\mathrm{n}=199,16.4 \pm 5.9 \mathrm{v} . \mathrm{n}=274,15.3 \pm 5.9, p=0.04)$. There were no significant differences between groups in: static defect diameter $(p=0.4)$, balloonsized diameter in the subgroup in whom stop-flow technique was used $(p=0.89)$, ratio of pulmonary to systemic blood flow ( $p=0.4$ ), or the proportion of patients undergoing balloon sizing $(p=0.4)$. Also, the choice of devices did not differ between subjects with deficient retro-aortic rim and those with larger rims $(p=0.25)$. Specifically, the ASO device was used in $68 \%$ of subjects with deficient retro-aortic rim and $71 \%$ of those with larger retro-aortic rims.

\section{Procedural outcomes}

Comparisons of procedural outcomes between the groups are summarized in Table 2.

Overall, $97 \%$ of defects were treated, with no difference in the proportion of subjects treated between those with deficient and larger retro-aortic rims $(\mathrm{p}=0.09)$. In those who underwent attempted device closure, technical failure occurred in $5.8 \%$ of all procedures. There was no difference in observed rate of technical failure between subjects with deficient retro-aortic $\operatorname{rim}(6.7 \%)$ and those with larger retro-aortic rim $(5.2 \%, p=0.19)$. Further, there were no differences in the individual risks of device embolization, malposition, residual shunt, or immediate retrieval between the two cohorts.

Embolization of a device occurred in 29 cases, of which $76 \%$ were successfully treated by transcatheter intervention. The remaining $24 \%(\mathrm{n}=6)$ cases underwent cardiac surgery. One other subject with a malpositioned HSO device underwent cardiac surgery without a subsequent catheterization. For the remaining 61 failure events, the response was not documented (Supplementary Table 2). Major early adverse events occurred in $4.1 \%$ of all cases, with no difference in risk observed between subjects with deficient $(3.5 \%)$ and nondeficient $(4.5 \%, p=0.34)$ retro-aortic rims. Cardiac arrest, tamponade, unplanned cardiac surgery, and unplanned other surgery were identified before analysis as major early adverse events that could be caused by a device erosion. These occurred in $1.2 \%$ of cases with no difference between subjects with deficient retro-aortic rims $(n=8 / 653,1.2 \%)$ and those with larger retro-aortic rim $(\mathrm{n}=11 / 911,1.2 \%, p=0.98)$.

Finally there were no significant differences in observed fluoroscopy $(p=0.11)$, sheath ( $p=0.81$ ), or total case time $(p=0.06)$ between the two cohorts.

\section{Multivariate models}

In multivariate models adjusting for pre-specified potential confounders, the risk of technical failure was not significantly higher with deficient retro-aortic rim (OR: 1.32, 95\% CI: $0.85-$ 2.05) (Table 3). Use of an HSO device was associated with increased risk of technical failure (OR: 1.88, 95\% CI: 1.09-3.25). Increasing static ASD size was also associated with 
increased risk of technical failure (OR: 1.08 for each increase of $1 \mathrm{~mm}, 95 \% \mathrm{CI}: 1.04-1.12$ ). An increase of $5 \mathrm{~mm}$ would be associated with an OR of 1.47.

In a similar multivariate model, deficient retro-aortic rim was not associated with increased risk of major early adverse events (OR: 0.71, 95\% CI: 0.41-1.22) (Table 4). Increasing static ASD size was associated with increased risk of adverse event (OR: 1.08 for each increase of $1 \mathrm{~mm}, 95 \%$ CI: 1.03-1.13), while increasing patient height was associated with decreased risk of major early adverse event (OR: 0.87 for each $10 \mathrm{~cm}, 95 \%$ CI: $0.78-0.97$ ).

Sensitivity analyses for models for technical failure (Supplementary Table 3) and major early adverse events (Supplementary Table 4) were performed. The addition of subjects with missing rim data did not significantly change the significance or magnitude of the association between retro-aortic rim size and outcome. There was no significant effect on other risk factors either.

To test if there was significant interaction between deficient retro-aortic rim and defect size, three post-hoc analyses were performed. In the first, an interaction term between deficient retro-aortic rim and static defect diameter was added to each model. In the second, an interaction term between deficient retro-aortic rim and a static defect size greater than $10 \mathrm{~mm}$ was added to the model. In the third, the ratio of defect size to septal diameter was added as a covariate to the model. None of these additional models altered the magnitude of the odds ratio for the primary outcome (data not shown). Deficient retro-aortic rim was not associated with increased risk of composite outcome (technical failure or major early adverse event) (Supplemental Table 5).

After adjusting for covariates, total case time (coefficient: 6.7 minutes 95\% CI: 1.6-11.8, $p=0.01$ ) and fluoroscopy time (coefficient: 1.5 minutes, $95 \%$ CI: 0.2 to $2.7, p=0.02$ ) were longer with deficient retro-aortic rim. For sheath time, the point estimate with deficient retro-aortic rim was consistent with a longer time (coefficient: 3.9 minutes) but the association was not statistically significant ( $95 \% \mathrm{CI}:-0.3$ to $8.0, p=0.07$ ).

Pre-specified secondary analyses were performed to determine whether the widely used definition of a deficient retro-aortic rim $(<5 \mathrm{~mm})$ is an effective discriminator for technical failure and adverse events. Splines and accompanying confidence intervals were plotted for the estimated odds ratio of each outcome over the range of retro-aortic rim dimensions. No significant association between the two was found. For technical failure, the spline suggests that $5 \mathrm{~mm}$ is a good cut point, as the odds ratio increases at rim sizes below $5 \mathrm{~mm}$ and decreases above $5 \mathrm{~mm}$ (Supplementary Figure 1). There was no pattern for major early adverse events (Supplemenatary Figure 2).

\section{Effect of choice of device on risk of technical failure and adverse outcome}

The observed risks of technical failure $(p=0.42)$ were not significantly different by device type (Table 5), and there were not statistically significant differences in the risk of device deployment, release, and retrieval; embolization; malposition; and residual shunt. However, though not significantly different, the embolization risk for $\mathrm{HSO}$ is $3.0 \%$, which is of greater magnitude than the risk in ASO (1.6\%), GSO (1.2\%), and other devices (1.9\%, $p=0.37)$. 
Inclusion of subjects with missing device rim measurements does not result in a change in the observed results (Supplementary Table 6).

The observed risk of early major adverse events in subjects undergoing device closure with "Other" devices (9.6\%) was subjectively higher than that seen in those receiving ASO (3.7\%), HSO (4.5\%), or GSO (1.2\%, $p=0.10)$ (Table 5). This difference was not significant. However, the driver for this observation is that there is a significantly higher risk of arrhythmia in the other category (7.7\%) compared to the risk in subjects receiving ASO $(1.7 \%)$, HSO $(2.1 \%)$, and GSO (1.2\%, p=0.03). The risk of other adverse events are not significantly different. When subjects with missing rim data are included, the increased risk of adverse events with other devices is statistically significant $(p=0.03)$ as is the increased risk of arrhythmia ( $p=0.02$, Supplementary Table 6).

\section{Discussion}

This multi-center retrospective cohort study assessed the contribution of retro-aortic rim to the risk of technical failure and major early adverse outcome. No significant association was identified between deficient retro-aortic rim and the risk of major early adverse events or technical failure. As exploratory analyses, independent risk factors for adverse events and technical failure were identified. Assessment of the risk of adverse events (such as device erosion) over longer time frames is not possible in the current registry, and for rare events such as device erosion even this large sample remains underpowered.

Though no statistically significant association was seen between deficient retro-aortic rim and the risk of technical failure, there are several factors that suggest such an association may exist: the point estimate in the initial model, the trend seen in the spline, and increased case times in multivariate modeling. The study population was fixed and no power calculations were performed prior to analysis. Even with a large study population there is risk of type II error. Also, unmeasured confounders may be present, obscuring a more robust association.

Other factors do appear to be more convincingly associated with the risk of technical failure. First, use of the HSO device appears to increase risk of technical failure. There is no guarantee that HSO devices were used in the same situations as ASO devices so caution should be exercised in interpreting this finding, but it does appear that the risk of technical failure is significantly higher with the HSO. No study to our knowledge has previously assessed whether device choice was associated with increased risk of technical failure. A contemporaneous multicenter study from the C3PO registry did not address differences in device type ${ }^{26}$. Post hoc analysis of the observed risk of adverse events to explore this issue demonstrated a suggestive but not significant increase in the risk of embolization with HSO. The change in risk was not associated with a higher rate of deploying, releasing, and retrieving HSO relative to other devices. Each component of technical failure is rare enough that multivariate analysis is not possible.

Second, increasing defect size was associated with increased risk of technical failure. Case series have described closing large defects in both adults and children ${ }^{27,28}$. The only study to 
our knowledge that addresses risk factors for these outcomes including other covariates was restricted to small children and did not identify defect size as a significant risk factor ${ }^{12}$. Post-hoc analyses were attempted to explore the effect of defect size relative to retro-aortic rim size but these did not reveal a significant interaction.

In contrast to technical failure, there were no indications that retro-aortic rim dimension and the risk of major early adverse events was associated. This was true of a sub-analysis of events consistent with early device erosion as well as a broader collection of major early adverse events. In terms of other covariates, increasing patient height was associated with decreased risk and increasing defect size was associated with increased risk of a major adverse event. This combination of risks should be considered when discussing with patients the relative risks and benefits of transcatheter and operative closure of ASD.

A potential concern raised by this analysis is that the rates of technical failure and major early adverse event rates are higher than previously reported $2,4-6,9-11,14,15,26,29-31$. Definitions of technical failure and major early adverse outcomes were chosen to be sensitive. For technical failure, many of the included outcomes can be addressed with repeat catheterization which has been accomplished without significant harm to the patient and while maintaining a cost advantage to device closure ${ }^{32}$. Several of the adverse outcomes are redundant with technical failure as described above (e.g. repeat catheterization). In addition, new arrhythmia, which accounted for $48 \%$ of adverse outcomes, includes transient rhythm disturbances, which are of lesser severity than the other listed outcomes. Alternatively, previous studies are from large centers with significant experience or in clinical trials, while the current study reports outcomes from a cross-section of current practice. This is supported by a recent multicenter case series from the $\mathrm{C} 3 \mathrm{PO}$ registry, which reports similarly high risk for new arrhythmia ( $2.4 \%$ vs. $2.0 \%$ in the current series), embolization (1.5\% vs. $1.9 \%$ in this series), and major adverse events (4.7\% vs. $4.1 \%$ in this series) ${ }^{26}$. It is also important to emphasize that in series with simultaneous measurement of adverse outcomes between surgical and device closure of ASD, transcatheter closure has performed at least as well as surgery regardless of the era in which data were recorded $2,8,31,32$.

Inclusion of residual shunt $\geq 3 \mathrm{~mm}$ as technical failure may be controversial to some. Allowing for small residual shunts may allow for the use of a relatively small device, with the theoretical benefit of reducing the risk of contact between device and atrial wall and reduced risk of device erosion. Also, the risk of a residual shunt must be weighed against the risk of placing a second device and/or operative closure. Some centers including our own who have not aggressively over-sized devices have reported relatively higher risk of trivial $(<1 \mathrm{~mm})$ shunt $(10 \%)$ and that many of these small shunts resolve over time ${ }^{15}$. In that series there were no larger residual shunts, and, to our knowledge, there is not published data on the natural history of larger residual shunts. This may be worth describing in future studies.

The optimal strategy in addressing a patient with an ASD with deficient retro-aortic rim remains a challenge. It is an extremely common anatomic variant ${ }^{12,14,15}$, which was confirmed in this study. It does not appear to increase the risk of early major adverse events with device closure, but the concern for longer-term risks (particularly device erosion) persists. It does appear, however, that $5 \mathrm{~mm}$ remains an appropriate cut-point to distinguish 
between the "deficient" and "sufficient" retro-aortic rim for the outcomes we can measure; we were not able to identify a cut-point with improved discrimination for these outcomes. Interestingly, despite the attention that the risk of device erosion with ASO devices has received, device choice was not different between subjects with deficient and larger retroaortic rims. In its current iteration, the IMPACT Registry could not be used to assess long term risks following transcatheter device deployment. The registry contains outcome data until hospital discharge. To study questions about longer-term outcomes, addition of a module to IMPACT that allows for longer-term follow-up or linkage of the IMPACT registry to other datasets is necessary.

\section{Limitations}

We acknowledge that there are limitations to this study. A significant minority of the potential study population was excluded because the retro-aortic rim dimension was not recorded. These subjects were excluded because they did not have information about the primary exposure for our study. Also, as noted earlier, the population with missing rim data was older, with a larger proportion of adult patients, smaller defects, and a higher proportion undergoing closure of ASD for stroke and migraine, suggesting they include a subgroup with qualitatively different defects than those with reported rim measurements.. In addition, sensitivity analyses including these subjects in multivariate models did not result in changes in the major findings of the study (Supplementary Tables 2 and 3), except that in the case of the HSO device the increased risk for technical failure was no longer significant.

Additionally, as a retrospective study, the population was fixed, and there is a risk of type II error. Post-hoc power calculations have been shown to be a potential source of bias ${ }^{33}$. We have included confidence intervals where appropriate to provide the reader the ability to interpret whether effect sizes reported are appropriate. The IMPACT® Registry contains self-reported data, and as of this time, auditing procedures have not been implemented. This introduces possible information bias, which is likely to bias results towards the null. The current cohort only contains the results of subjects referred for trans-catheter ASD closure, and is not able to address the comparable results in similar populations referred to operative ASD closure. The results of operative ASD closure in comparison to transcatheter ASD closure have been reported previously $2,8,10,32,34,35$. However, in the current era, there have not been reports about the effect that concern about deficient retro-aortic rim has had on physician and family choice between operative and transcatheter ASD closure.

\section{Conclusion}

Accepting these limitations, we conclude that deficient retro-aortic rim is highly prevalent. There was not a significant association between deficient retro-aortic rim and technical failure or major early adverse events. Other covariates independently associated with these outcomes were identified. Studying long-term risk of adverse outcomes is important, but cannot be accomplished with the current design of the registry.

\section{Supplementary Material}

Refer to Web version on PubMed Central for supplementary material. 


\section{Acknowledgments}

Funding sources: Dr. O'Byrne received support from the NIH [T32 HL007915] and Entelligence Young Investigator grant. This research was supported by the American College of Cardiology's National Cardiovascular Data Registry (NCDR). The views expressed in this manuscript represent those of the author(s), and do not necessarily represent the official views of the NCDR or its associated professional societies identified at CVQuality.ACC.org/NCDR, nor are they those of any funding agencies.

Dr. Dori receives research support from Siemens. Dr. Gillespie is a consultant for Medtronic. Doctors Glatz and Rome are consultants for Bristol Myers Squib Inc.

\section{REFERENCE}

1. King TD, Thompson SL, Steiner C, Mills NL. Secundum atrial septal defect. Nonoperative closure during cardiac catheterization. JAMA. 1976; 235:2506-2509. [PubMed: 946659]

2. Du ZD, Hijazi ZM, Kleinman CS, Silverman NH, Larntz K. Amplatzer Investigators. Comparison between transcatheter and surgical closure of secundum atrial septal defect in children and adults: results of a multicenter nonrandomized trial. J Am Coll Cardiol. 2002; 39:1836-1844. [PubMed: 12039500]

3. Levi DS, Moore JW. Embolization and retrieval of the Amplatzer septal occluder. Cathet Cardiovasc Intervent. 2004; 61:543-547.

4. Chessa M, Carminati M, Butera G, Bini RM, Drago M, Rosti L, Giamberti A, Pomè G, Bossone E, Frigiola A. Early and late complications associated with transcatheter occlusion of secundum atrial septal defect. J Am Coll Cardiol. 2002; 39:1061-1065. [PubMed: 11897451]

5. Wang J-K, Tsai S-K, Wu M-H, Lin M-T, Lue H-C. Short- and intermediate-term results of transcatheter closure of atrial septal defect with the Amplatzer Septal Occluder. Am Heart J. 2004; 148:511-517. [PubMed: 15389241]

6. DiBardino DJ, McElhinney DB, Kaza AK, Mayer JE Jr. Analysis of the US Food and Drug Administration Manufacturer and User Facility Device Experience database for adverse events involving Amplatzer septal occluder devices and comparison with the Society of Thoracic Surgery congenital cardiac surgery database. J Thorac Cardiovasc Surg. 2009; 137:1334-1341. [PubMed: 19464444]

7. Delaney JW, Li JS, Rhodes JF. Major Complications Associated with Transcatheter Atrial Septal Occluder Implantation: A Review of the Medical Literature and the Manufacturer and User Facility Device Experience (MAUDE) Database. Cong heart dis. 2007; 2:1-9.

8. Butera G, Biondi-Zoccai G, Sangiorgi G, Abella R, Giamberti A, Bussadori C, Sheiban I, Saliba Z, Santoro T, Pelissero G, Carminati M, Frigiola A. Percutaneous versus surgical closure of secundum atrial septal defects: a systematic review and meta-analysis of currently available clinical evidence. EuroIntervention. 2011; 7:377-385. [PubMed: 21729841]

9. Latson LA, Jones TK, Jacobson J, Zahn E, Rhodes JF. Analysis of factors related to successful transcatheter closure of secundum atrial septal defects using the HELEX septal occluder. Am Heart J. 2006; 151:1129.e7-1129.e11.

10. Kutty S, Abu Hazeem A, Brown K, Danford CJ, Worley SE, Delaney JW, Danford DA, Latson LA. Long-Term (5- to 20-Year) Outcomes After Transcatheter or Surgical Treatment of Hemodynamically Significant Isolated Secundum Atrial Septal Defect. Am J Cardiol. 2012; 109:1348-1352. [PubMed: 22335856]

11. Vincent RN, Raviele AA, Diehl HJ. Single-center experience with the HELEX septal occluder for closure of atrial septal defects in children. J Interv Cardiol. 2003; 16:79-82. [PubMed: 12664820]

12. Petit CJ, Justino H, Pignatelli RH, Crystal MA, Payne WA, Ing FF. Percutaneous Atrial Septal Defect Closure in Infants and Toddlers: Predictors of Success. Pediatr Cardiol. 2012; 34:220-225. [PubMed: 22806712]

13. Amin Z, Hijazi ZM, Bass JL, Cheatham JP, Hellenbrand WE, Kleinman CS. Erosion of Amplatzer septal occluder device after closure of secundum atrial septal defects: Review of registry of complications and recommendations to minimize future risk. Cathet Cardiovasc Intervent. 2004; 63:496-502. 
14. Butera G, Romagnoli E, Carminati M, Chessa M, Piazza L, Negura D, Giamberti A, Abella R, Pomè G, Condoluci C, Frigiola A. Treatment of isolated secundum atrial septal defects: Impact of age and defect morphology in 1,013 consecutive patients. Am Heart J. 2008; 156:706-712. [PubMed: 18926151]

15. O'Byrne ML, Glatz AC, Sunderji S, Mathew AE, Goldberg DJ, Dori Y, Rome JJ, Gillespie MJ. Prevalence of Deficient Retro-Aortic Rim and Its Effects on Outcomes in Device Closure of Atrial Septal Defects. Pediatr Cardiol. 2014; 35:1181-1190. [Internet]. Available from: http:// link.springer.com/10.1007/s00246-014-0914-6. [PubMed: 24823883]

16. O'Byrne ML, Glatz AC, Goldberg DJ, Shinohara R, Dori Y, Rome JJ, Gillespie MJ. Accuracy of Transthoracic Echocardiography in Assessing Retro-aortic Rim prior to Device Closure of Atrial Septal Defects. Cong heart dis. 2014:1-9.

17. Martin GR, Beekman RH, Ing FF, Jenkins KJ, McKay CR, Moore JW, Ringel RE, Rome JJ, Ruiz CE, Vincent RN. The IMPACT registry: IMproving Pediatric and Adult Congenital Treatments. Sem Thorac and Cardiovasc Surg: Ped Card Surg Annual. 2010; 13:20-25.

18. Moore JW, Vincent RN, Beekman RH, Benson L, Bergersen L, Holzer R, Jayaram N, Jenkins K, Li Y, Ringel R, Rome J, Martin GR. NCDR IMPACT Steering Committee. Procedural results and safety of common interventional procedures in congenital heart disease: initial report from the national cardiovascular data registry. J Am Coll Cardiol. 2014; 64:2439-2451. [PubMed: 25500227]

19. Vincent RN, Moore J, Beekman RH, Benson L, Bergersen L, Holzer R, Jayaram N, Jenkins K, Ringel R, Rome J, Martin GR. Procedural characteristics and adverse events in diagnostic and interventional catheterisations in paediatric and adult CHD: initial report from the IMPACT Registry. Cardiology in the Young. 2015:1-9.

20. Messenger JC, Ho KKL, Young CH, Slattery LE, Draoui JC, Curtis JP, Dehmer GJ, Grover FL, Mirro MJ, Reynolds MR, Rokos IC, Spertus JA, Wang TY, Winston SA, Rumsfeld JS, Masoudi FA. NCDR Science and Quality Oversight Committee Data Quality Workgroup. The National Cardiovascular Data Registry (NCDR) Data Quality Brief: the NCDR Data Quality Program in 2012. J Am Coll Cardiol. 2012; 60:1484-1488. [PubMed: 22999725]

21. Diab K, Kenny D, Hijazi ZM. Erosions, erosions, and erosions! Device closure of atrial septal defects: How safe is safe? Cathet Cardiovasc Intervent. 2012; 80:168-174.

22. Amin Z. Echocardiographic predictors of cardiac erosion after Amplatzer septal occluder placement. Catheter Cardiovasc Interv. 2014; 83:84-92. [PubMed: 24038861]

23. Desquilbet L, Mariotti F. Dose-response analyses using restricted cubic spline functions in public health research. Statist Med. 2010; 29:1037-1057.

24. O'Byrne ML, Glatz AC, Mercer-Rosa L, Gillespie MJ, Dori Y, Goldmuntz E, Kawut S, Rome JJ. Trends in pulmonary valve replacement in children and adults with tetralogy of fallot. Am J Cardiol. 2015; 115:118-124. [PubMed: 25456860]

25. O'Byrne ML, Glatz AC, Shinohara RT, Jayaram N, Gillespie MJ, Dori Y, Rome JJ, Kawut S. Effect of center catheterization volume on risk of catastrophic adverse event after cardiac catheterization in children. Am Heart J. 2015; 169:823.e5-832.e5. [PubMed: 26027620]

26. El-Said H, Hegde S, Foerster S, Hellenbrand W, Kreutzer J, Trucco SM, Holzer R, Burch G, Mirani A, Nicolas R, Porras D, Bergersen L, Moore J. Device therapy for atrial septal defects in a multicenter cohort: acute outcomes and adverse events. Catheter Cardiovasc Interv. 2015; 85:227233. [PubMed: 25257700]

27. Baruteau A-E, Petit J, Lambert V, Gouton M, Piot D, Brenot P, Angel C-Y, Houyel L, Le Bret E, Roussin R, Ly M, Capderou A, Belli E. Transcatheter closure of large atrial septal defects: feasibility and safety in a large adult and pediatric population. Circ Cardiovasc Interv. 2014; 7:837-843. [Internet]. [PubMed: 25423959]

28. Dalvi B, Pinto R, Gupta A. Device closure of large atrial septal defects requiring devices $>$ or $=20$ $\mathrm{mm}$ in small children weighing <20 kg. Catheter Cardiovasc Interv. 2008; 71:679-686. [PubMed: 18360866]

29. Jones TK, Latson LA, Zahn E, Fleishman CE, Jacobson J, Vincent R, Kanter K. Results of the U.S. Multicenter Pivotal Study of the HELEX Septal Occluder for Percutaneous Closure of Secundum Atrial Septal Defects. J Am Coll Cardiol. 2007; 49:2215-2221. [PubMed: 17543643] 
30. Aytemir K, Oto A, Ozkutlu S, Canpolat U, Kaya EB, Yorgun H, Sahiner L, Sunman H, Ateş AH, Kabakçı G. Transcatheter interatrial septal defect closure in a large cohort: midterm follow-up results. Cong heart dis. 2013; 8:418-427.

31. Rosas M, Zabal C, Garcia-Montes J, Buendia A, Webb G, Attie F. Transcatheter versus surgical closure of secundum atrial septal defect in adults: impact of age at intervention. A concurrent matched comparative study. Cong heart dis. 2007; 2:148-155.

32. O'Byrne ML, Gillespie MJ, Shinohara RT, Dori Y, Rome JJ, Glatz AC. Cost comparison of transcatheter and operative closures of ostium secundum atrial septal defects. Am Heart J. 2015; 169:727.e2-735.e2. [PubMed: 25965721]

33. Sun GW, Shook TL, Kay GL. Inappropriate use of bivariable analysis to screen risk factors for use in multivariable analysis. J Clin Epidemiol. 1996; 49:907-916. [PubMed: 8699212]

34. Mylotte D, Quenneville SP, Kotowycz MA, Xie X, Brophy JM, Ionescu-Ittu R, Martucci G, Pilote L, Therrien J, Marelli AJ. Long-term cost-effectiveness of transcatheter versus surgical closure of secundum atrial septal defect in adults. Int J Cardiol. 2014; 172:109-114. [Internet]. Available from: http://dx.doi.org/10.1016/j.ijcard.2013.12.144. [PubMed: 24485223]

35. Hughes ML, Maskell G, Goh TH, Wilkinson JL. Prospective comparison of costs and short term health outcomes of surgical versus device closure of atrial septal defect in children. Heart. 2002; 88:67-70. [PubMed: 12067948] 
Device closure of ASD in IMPACT $\mathrm{n}=3557$

77 Centers

\section{Analytic Cohort}

Excluded subjects

1) Multiple ASD ( $n=156)$

2) Multi-fenestrated ASD

$$
(n=389)
$$

3) Additional trans-catheter procedure $(n=100)$

4) Prior cardiac surgery $(n=141)$

5) Missing rim measurement $(n=1207)$

\section{Centers}

Figure 1.

Study population 
Table 1

Study population

\begin{tabular}{|c|c|c|c|}
\hline & Deficient retro-aortic rim $(<5 \mathrm{~mm})$ & Adequate retro-aortic rim ( $\triangle 5 \mathrm{~mm}$ ) & $p$ \\
\hline $\mathrm{n}$ & 653 & 911 & \\
\hline Female sex \% (n) & $66 \%(427)$ & $63 \%(573)$ & 0.31 \\
\hline Age (years) & 5 (IQR: 4-11) & 7 (IQR: 4-15) & $<0.001$ \\
\hline \multicolumn{4}{|l|}{ Age by category $\%(\mathrm{n})$} \\
\hline$<30$ days & $0.3 \%(2)$ & $0.1 \%(1)$ & $<0.001$ \\
\hline 30 days to 1 year & $2 \%(12)$ & $1 \%(9)$ & \\
\hline 1 year to 18 years & $90 \%(585)$ & $82 \%(744)$ & \\
\hline$>18$ years & $8 \%(54)$ & $17 \%(157)$ & \\
\hline \multicolumn{4}{|l|}{ Race } \\
\hline White & $74 \%(483)$ & $77 \%(701)$ & 0.02 \\
\hline Black & $15 \%(96)$ & $10 \%(90)$ & \\
\hline Asian & $5 \%(35)$ & $7 \%(66)$ & \\
\hline Other/missing & $6 \%(39)$ & $6 \%(54)$ & \\
\hline Hispanic ethnicity & $19 \%(33 / 620)$ & $18 \%(45 / 866)$ & 0.73 \\
\hline \multicolumn{4}{|l|}{ Insurance payer } \\
\hline Private & $47 \%(304)$ & $53 \%(480)$ & 0.06 \\
\hline Public (Medicaid or Medicare) & $35 \%(229)$ & $31 \%(281)$ & \\
\hline Other & $18 \%(120)$ & $16 \%(150)$ & \\
\hline \multicolumn{4}{|l|}{ Indication for closure } \\
\hline Right ventricle dilation & $95 \%(619)$ & $92 \%(836)$ & 0.08 \\
\hline Chronic lung disease & $0.8 \%(5)$ & $0.7 \%(6)$ & \\
\hline Failure to thrive & $0.9 \%(6)$ & $0.4 \%(4)$ & \\
\hline Recurrent respiratory infections & $0.3 \%(2)$ & $0.3 \%(3)$ & \\
\hline Ventilator dependent & $0.2 \%(1)$ & $0 \%(0)$ & \\
\hline Cyanosis & $0.6 \%(4)$ & $1.2 \%(11)$ & \\
\hline Prevention of stroke & $2.0 \%(13)$ & $5.1 \%(46)$ & \\
\hline Migraine & $0.3 \%(2)$ & $0.4 \%(4)$ & \\
\hline Missing & $0.2 \%(1)$ & $0.1 \%(1)$ & \\
\hline ASD septal length (mm) & $33.8 \pm 9.2$ & $35.5 \pm 9.1$ & $<0.001$ \\
\hline ASD defect size (mm) & $13.6 \pm 5.6$ & $13.3 \pm 6.2$ & 0.4 \\
\hline Ratio of Qp:Qs* & $1.9 \pm 0.7$ & $1.9 \pm 0.8$ & 0.79 \\
\hline Trainee present & $52 \%(336)$ & $48 \%(435)$ & 0.16 \\
\hline Anesthesiologist present & $97 \%(635)$ & $91 \%(885)$ & 0.16 \\
\hline Balloon sizing & & & 0.40 \\
\hline Stop-flow technique & $15 \%(101)$ & $11 \%(100)$ & \\
\hline Stretch technique & $30 \%$ (199) & $30 \%(274)$ & \\
\hline
\end{tabular}

Catheter Cardiovasc Interv. Author manuscript; available in PMC 2018 January 01. 


\begin{tabular}{|r|c|c|c|}
\hline & Deficient retro-aortic rim $(<\mathbf{5 m m})$ & Adequate retro-aortic rim $(\mathbf{5 m m})$ & $\boldsymbol{p}$ \\
\hline Not performed & $53 \%(348)$ & $58 \%(525)$ & \\
\hline Balloon size diameter $(\mathrm{mm})$ & & & \\
\hline Stop-flow technique & $16.1 \pm 5.7(\mathrm{n}=101)$ & $16.2 \pm 5.9(\mathrm{n}=100)$ & 0.89 \\
\hline Stretch technique & $16.4 \pm 5.9(\mathrm{n}=199)$ & $15.3 \pm 5.9(\mathrm{n}=274)$ & 0.04 \\
\hline Device used & & & 0.25 \\
\hline Amplatzer septal occluder & $68 \%(447)$ & $71 \%(651)$ & \\
\hline Helex septal occluder & $22 \%(145)$ & $21 \%(188)$ & \\
\hline Gore septal occluder & $5 \%(33)$ & $5 \%(48)$ & \\
\hline Other & $4 \%(28)$ & $3 \%(24)$ & \\
\hline
\end{tabular}

* 87 missing in deficient retro-aortic rim group, 131 missing in the non-deficient rim group 


\section{Table 2}

Procedural outcomes

\begin{tabular}{|c|c|c|c|}
\hline & $\begin{array}{c}\text { Deficient retro-aortic rim } \\
\qquad(<5 \mathrm{~mm})\end{array}$ & $\begin{array}{l}\text { Adequate retro-aortic } \\
\text { rim }(\triangle \mathrm{mm})\end{array}$ & $p$ \\
\hline Defect treated & $96 \%(625)$ & $97 \%(887)$ & 0.09 \\
\hline Technical failure & $6.7 \%(44)$ & $5.2 \%(47)$ & 0.19 \\
\hline Device embolization & $2.2 \%(14)$ & $1.7 \%(15)$ & 0.48 \\
\hline Malposition or thrombus with re-intervention & $0.3 \%(2)$ & $0.3 \%(3)$ & 0.94 \\
\hline Residual shunt ( $23 \mathrm{~mm}$ ) & $1.6 \%(10)$ & $1.4 \%(12)$ & 0.82 \\
\hline Device deployed released and immediately retrieved & $2.9 \%(18)$ & $1.9 \%(17)$ & 0.23 \\
\hline Adverse event ${ }^{*}$ & $3.5 \%(23)$ & $4.5 \%(41)$ & 0.34 \\
\hline Cardiac arrest & $0 \%(0)$ & $0.2 \%(2)$ & 0.23 \\
\hline Embolic stroke & $0.3 \%(2)$ & $0 \%(0)$ & 0.10 \\
\hline New arrhythmia & $1.5 \%(10)$ & $2.3 \%(21)$ & 0.28 \\
\hline Repeat catheterization & $0.3 \%(2)$ & $0.9 \%(8)$ & 0.16 \\
\hline Tamponade & $0 \%(0)$ & $0.2 \%(2)$ & 0.23 \\
\hline Unplanned cardiac surgery & $1.1 \%(7)$ & $0.7 \%(6)$ & 0.38 \\
\hline Unplanned other surgery & $0.2 \%(1)$ & $0.1 \%(1)$ & 0.82 \\
\hline Vascular complication & $0.2 \%(1)$ & $0.3 \%(3)$ & 0.50 \\
\hline Total case time (minutes) & $153.0 \pm 56.2$ & $148.2 \pm 43.9$ & 0.06 \\
\hline Sheath time (minutes) & $77.5 \pm 44.0$ & $77.0 \pm 35.9$ & 0.81 \\
\hline Fluoroscopy time (minutes) & $16.3 \pm 11.8$ & $15.3 \pm 12.0$ & 0.11 \\
\hline
\end{tabular}

* No cases with air embolus, new valve regurgitation, initiation of dialysis, initiation of mechanical circulatory support, or unplanned vascular surgery were recorded. 
Table 3

Results of multivariable model of risk factors for technical failure

\begin{tabular}{|c|c|c|c|}
\hline & Odds Ratio & $95 \% \mathrm{CI}$ & $p$ \\
\hline Deficient retro-aortic rim & 1.32 & $0.85-2.05$ & 0.22 \\
\hline Age (per 1 year) & 1.00 & $0.98-1.02$ & 0.97 \\
\hline Female sex & 1.25 & $0.78-2.00$ & 0.35 \\
\hline Height (for each $10 \mathrm{~cm}$ ) & 0.95 & $0.86-1.05$ & 0.32 \\
\hline Static ASD size (for each $1 \mathrm{~mm}$ increase) & 1.08 & $1.04-1.12$ & $<0.0001$ \\
\hline Trainee present & 0.69 & $0.44-1.07$ & 0.10 \\
\hline \multicolumn{4}{|l|}{ Balloon sizing } \\
\hline Not measured & 1 & $\mathrm{n} / \mathrm{a}$ & $\mathrm{n} / \mathrm{a}$ \\
\hline Stretch technique & 1.10 & $0.51-2.36$ & 0.81 \\
\hline Stop-flow technique & 0.97 & $0.47-1.99$ & 0.93 \\
\hline Missing & 1.27 & $0.14-11.11$ & 0.83 \\
\hline \multicolumn{4}{|l|}{ Device } \\
\hline Amplatzer septal occluder & 1 & $\mathrm{n} / \mathrm{a}$ & $\mathrm{n} / \mathrm{a}$ \\
\hline Helex septal occluder & 1.88 & $1.09-3.25$ & 0.02 \\
\hline Gore septal occluder & 1.02 & $0.30-3.44$ & 0.98 \\
\hline Other septal occluder & 0.20 & $0.03-1.53$ & 0.12 \\
\hline
\end{tabular}


Table 4

Results of multivariable model of risk factors for major early adverse events

\begin{tabular}{|c|c|c|c|}
\hline & Odds Ratio & $95 \% \mathrm{CI}$ & $p$ \\
\hline Deficient retro-aortic rim & 0.71 & $0.41-1.22$ & 0.21 \\
\hline Age (per 1 year) & 1.02 & $0.99-1.04$ & 0.17 \\
\hline Female sex & 1.07 & $0.62-1.84$ & 0.82 \\
\hline Height (for each $10 \mathrm{~cm}$ ) & 0.87 & $0.78-0.97$ & 0.02 \\
\hline Static ASD size (for each $1 \mathrm{~mm}$ increase) & 1.08 & $1.03-1.13$ & 0.001 \\
\hline Trainee present & 0.95 & $0.56-1.60$ & 0.84 \\
\hline \multicolumn{4}{|l|}{ Balloon sizing } \\
\hline Not measured & 1 & $\mathrm{n} / \mathrm{a}$ & $\mathrm{n} / \mathrm{a}$ \\
\hline Stretch technique & 1.22 & $0.49-3.04$ & 0.67 \\
\hline Stop-flow technique & 1.08 & $0.45-2.57$ & 0.86 \\
\hline Missing & 1.61 & $0.17-15.28$ & 0.68 \\
\hline \multicolumn{4}{|l|}{ Device } \\
\hline Amplatzer septal occluder & 1 & $\mathrm{n} / \mathrm{a}$ & $\mathrm{n} / \mathrm{a}$ \\
\hline Helex septal occluder & 1.91 & $0.98-3.72$ & 0.06 \\
\hline Gore septal occluder & 0.51 & $0.07-3.86$ & 0.52 \\
\hline Other septal occluder & 1.96 & $0.68-5.63$ & 0.21 \\
\hline
\end{tabular}




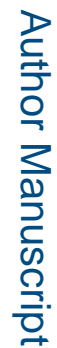

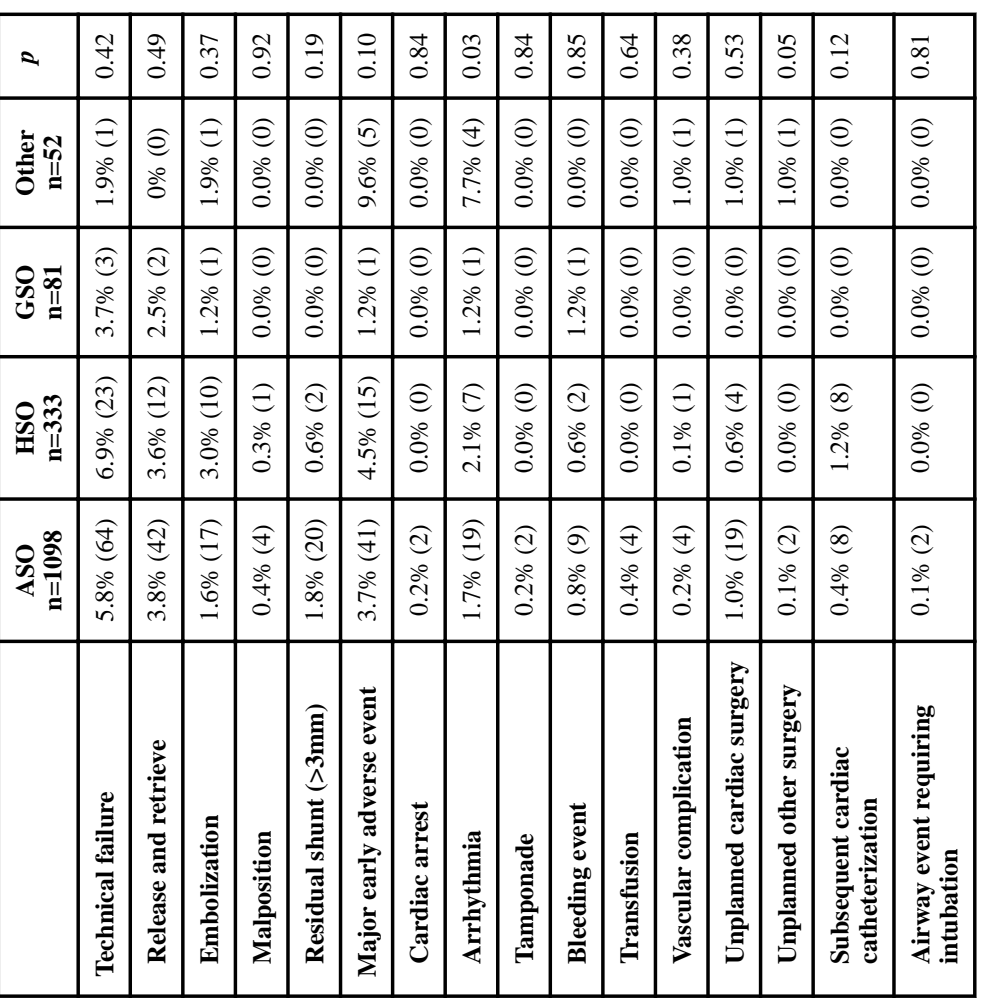

